\title{
ALFP-FINGERPRINTING FOR CERTIFICATION OF Aspergillus niger L-4, THE CITRIC ACID COMMERCIAL PRODUCER
}

\author{
N.Yu. SHAROVA 1 , V.I. SAFRONOVA ${ }^{2}$
}

${ }^{1}$ All-Russian Research Institute for Food Additives, Federal Agency of Scientific Organizations, 55, Liteinyi prosp., St. Petersburg, 191014 Russia, e-mail natalya_sharova1@mail.ru;

${ }_{2}^{2}$ All-Russian Research Institute for Agricultural Microbiology, Federal Agency of Scientific Organizations, 3, sh. Podbel'skogo, St. Petersburg, 196608 Russia

Received January 11, 2016

\section{Abstract}

Citric acid plays an important role in cellular respiration, and participates in oxidation processes as a natural antioxidant and synergist antioxidant, inhibiting plant oxidoreductase, together with ascorbic acid. Citric acid is effective against east and bacterial pathogens, and can be used in ensilaging. Citric acid is an antimicrobial agent alternative to fodder antibiotics prohibited in European countries. It is metabolized in plants, animals and humans with no adverse effect. Aspergillus niger is the citric acid common producer. So far as cultural and morphological features are not enough to confirm strain authenticity essential for effective commercial product manufacturing, we used genetic certification of the strain. Note, in 2015 in wide range genetic study of Aspergillus flavus diversity the specific ALFP patterns were found though their practical aspects were not discussed (D. Singh et al., 2015). Herein, we studies osmophilic commercial strain Aspergillus niger L-4, the citric acid producer derived due to chemical and UV mutagenesis and spontaneous mutations, using optimized AFLP-fingerpinting with 12 different primers. Specific AFLP patterns were obtained for Aspergillus niger L-4 authentification. Mse_cc GATGAGTCCTGAGTAACC and Eco_ac (FAM) GACTGCGTACCAATTAC primers were shown to be optimal providing maximum number of DNA fragments in the range of 33.68 to 593.78 bp ( 89 fragments) subject to the described method of fingerprinting and computer processing. The primers are effective regardless of sample volume. The resulting profiles can be used to authenticate the strain Aspergillus niger L-4 from different sources.

Keywords: Aspergillus niger, citric acid producer, genetic profiling, AFLP-fingerprinting

Citric acid plays the important role in biochemical reactions of cellular respiration, the biological significance of which is most weighty compared to other biochemical processes in cells. It is involved in oxidation as natural antioxidant and a synergist of antioxidants, inhibiting, along with ascorbic acid, oxidoreducteses in plant tissue $[1,2]$. Citric acid binds $\mathrm{Fe}^{+3}$ ions in colorless potato tubers improving taste. In the course of long-term storage of tuber crops at low temperature $\left(-4{ }^{\circ} \mathrm{C}\right.$ and $\left.-8{ }^{\circ} \mathrm{C}\right)$ malic, fumaric and tartaric acids levels decrease where as citric acids increases [3]. At positive temperatures the antioxidative activity in plant tissues is not enough to slow down oxidation, so this necessitates using preparations with antioxidant activity. Citric acids is effective in control of contamination with east and bacterial pathogens in food products [4, 5]. Due to acidic conditions citric acid provides binding bivalent cations of bacterial oxidoreductases to chelates [5], it can be easy applied and removed from seeds, and is used to treat seeds for neutralization of fungal and bacterial pathogens for safe long-term storage [6). So citric acid is considered effectively alternative to antimicrobial preparations with other acting mechanism, particularly, feed antibiotics prohibited in Europe. Products of citric acid metabolism in the body have no adverse effect.

Since citric acid synthesis occurs in each living things, it seems biotechnologically reasonable to consider tricarbonic acid cycle (or Krebs cycle, TCC) 
as universal source of citric acid. In microorganisms biochemical reactions are highly labile. Naturally microbes do not produce an excess of metabolites, though it may be due to changed parameters of incubation, or a proportion of gene induction and repression. At that, a resulting shift in the character of biochemical pathways, including TCC, occurs.

Micromycete Aspergillus niger is a common producer of citric acid, and its authenticity must be under control to provide stable production parameters. For commercial use the high producing strains of $A$. niger are derived which meets normative technological indicators [7]. However, these are not enough to ascertain the strain authenticity. A set of cultural and morphological traits is not sufficient to provide a complete assessment of individual strain within a biological species. Genetic uniformity is characteristic of commercial aspergillus strains producing citric acid, so that necessitate producing periodically pure cultures (elite lines) from a typical conidia or colony [7]. Thus, a genetic authenticity becomes of special importance. AFLP (amplified fragments length polymorphism) fingerprinting is a common technique in molecular genetics of microorganism. Using AFLP-fingerprinting, the differences have been successfully found between close related strains in different taxonomic groups including rhizobia [812], lactobacteria [13-16], and myceliar fungi Trichoderma and Aspergillus [17-20]. AFLP-fingerprinting is high reproducible, so it may be considered promising to authenticate microorganisms [21]. Each strain produces a unique pattern of amplified DNA fragment (AFLP-pattern), which is suitable for computerized processing to compare with other strain and can be used as «genetic passport». Earlier we have optimized the AFLP-fingerprinting protocol for strains of agricultural microorganisms [22].

Cultural and morphological features of $A$. niger strains have been shown not enough to identify individual specific traits [7]. RAPD-PCR (random amplification of polymorphic DNA) with universal primers AS15inv, L 15/AS19 and AA2c producing specific sets of genome DNA amplicons, was more effective for genotyping selected strains in this species [7].

Herein, the AFLP-patterns for osmophilic commercial strain Aspergillus niger L-4, the commercial producer of citric acids, are first reported. Specific primers, Mse_cc GATGAGTCCTGAGTAACC and Eco_ac (FAM) GACTGCGTACCAATTAC, are optimized to produce 89 fragments ranged from 33.68 to 593.78 bp in size.

Our aim was a genome AFLP-fingerprinting of commercial citric acid producer Aspergillus niger L-4 using 12 combination of primers to obtain unique «genetic passport» for strain authentication.

Technique. Conidia of osmophilic commercial strain Aspergillus niger L4 (collection of All-Russian Research Institute for Food Additives) were the biological material.

For DNA isolation conidia were thoroughly homogenized in mortar with pestle, then frozen, thawed and homogenized again (the procedure was repeted 4 times). After an aliquot $500 \mu \mathrm{l} 2 \times$ CTAB buffer $(2 \%$ CTAB, $1.4 \mathrm{M} \mathrm{NaCl}, 20$ $\mathrm{mM}$ EDTA, $100 \mathrm{mM}$ Tris- $\mathrm{HCl}, \mathrm{pH} 8.0$ ) was added, it was placed in $1.5 \mathrm{ml}$ eppendorf and incubated $60 \mathrm{~min}$ at $65{ }^{\circ} \mathrm{C}$ using vortex for periodical shaking. For extraction repeated twice the chloroform:isoamyl alcohol $(24: 1, \mathrm{v} / \mathrm{v})$ was used. DNA was precipitated with an equal volume of isopropanol $(5 \mathrm{~min}$ at room temperature), centrifuged ( $\left.2 \mathrm{~min}, 14000 \mathrm{~min}^{-1}\right)$, the supernatant was air dried. Then the precipitate was dissolved in $200 \mu \mathrm{l} 70 \%$ ethanol, centrifuged $7 \mathrm{~s}$, and alcohol was removed. Air dried DNA precipitate was suspended in $50 \mu \mathrm{l}$ $\mathrm{H}_{2} \mathrm{O}$ (MQ). Isolated DNA was stored at $-20^{\circ} \mathrm{C}$.

DNA purification was performed by $1 \%$ agarose gel electrophoresis in 
a Sub Cell GT (Bio-Rad, USA) chamber for $60 \mathrm{~min}$ at $100 \mathrm{~V} . \lambda$ /HindIII Marker $(0.5 \mu \mathrm{g} / \mu \mathrm{l}$, Fermentas, USA; $1 \mu \mathrm{l})$ and DNA Gel Loading Dye (Thermo Scientific, USA; $5 \mu \mathrm{l}$ ) was added to the probes. DNA-containing slice was cut out of the gel and placed into eppendorf. Three volumes (to gel slice volume) of agarose solvent (3 M GITS, $20 \mathrm{mM}$ EDTA, $10 \mathrm{mM}$ Tris-HCl, pH 6.8; Triton X-100 to $40 \mathrm{mg} / \mathrm{ml}$ ) was added to final volume of $500 \mu \mathrm{l})$. Tubes were incubated in thermostat at $65{ }^{\circ} \mathrm{C}$ for $5 \mathrm{~min}$, stirring occasionally. To the dissolved gel slice the Silica reagent (Fermentas, USA; $40 \mu \mathrm{l}$ ) was added, and the probe was vortexed for $15 \mathrm{~min}$ and then centrifuged for $1 \mathrm{~min}$ at $2700 \mathrm{~min}^{-1}$. After the first centrifugation the supernatant was poured out, after second it was removed using needle, and finally it was completely dried. Dry precipitate was rinsed in a $250 \mu \mathrm{l}$ solution containing $25 \%$ ethanol, $25 \%$ isopropanol, $100 \mathrm{mM} \mathrm{NaCl}, \mathrm{pH} 8.8$ ) and centrifuged $1 \mathrm{~min}$ at $2700 \mathrm{~min}^{-1}$. Liquid was poured out dry, and the precipitate was rinsed in $200 \mu 196 \%$ ethanol with the supernatant removing. The residue was dried for $10-15$ min to evaporation of the alcohol and dissolved in $15 \mu$ l eluting solution $(10 \mathrm{mM}$ Tris- $\mathrm{HCl}, \mathrm{pH} 8.0)$. After 5 min incubation at $65{ }^{\circ} \mathrm{C}$ and $15 \mathrm{~min}$ vortexing at room temperature, followed by one more incubation for $5 \mathrm{~min}$ at $65{ }^{\circ} \mathrm{C}$, the samples was centrifuged $1 \mathrm{~min}$ at $14000 \mathrm{~min}^{-1}$ with removing supernatant to eppendorfs. To assay DNA concentration the $1 \%$ agarose gel electrophoresis at $100 \mathrm{~V}$ for $60 \mathrm{~min}$ was used. A $3 \mu \mathrm{l}$ DNA sample with $1 \mu$ l loading dye were poured per well; $\lambda /$ HindIII Marker $(0.5 \mu \mathrm{g} / \mu \mathrm{l})$ was a marker $(1 \mu \mathrm{l}$ marker and $5 \mu \mathrm{l}$ dye were mixed).

Aliquot $10 \mu \mathrm{l}$ of purified DAN was subjected to restriction and ligation using 2.5 U EcoRI and MseI (Thermo Scientific, USA); $2.5 \mathrm{U}_{4} \mathrm{~T}_{4}$ ligase (Thermo Scientific, USA); two oligonucleotide adapters for each site adEco1 CTCGTAGAC-TGCGTACC and adEco2 AATTGGTACGCAGTCTAC for EcoRI, adMse1 GACGAGAGTCCTGAG and adMse2 TACTCAGGACTCAT for MseI (5 pmol each); the mixture was allowed for 18 hours at $37^{\circ} \mathrm{C}$. $\mathrm{T}_{4} \mathrm{DNA}$ ligase reaction buffer (Thermo Scientific, USA) was used.

For final fingerprinting, to aliquot $4 \mu \mathrm{l}$ reaction mixture at the stage of restriction and ligation the $2.5 \mu \mathrm{l} 10 \times$ polymerase buffer, $2.5 \mu \mathrm{l} 1,5 \mathrm{MM}$ dNTPs, two selective primers (10 pmol each), of which one was FAM-marked, 1 U Taq DNA polymerase (Fermenta», USA) were added. All possible primer combinations were tested - Mse_0 GATGAGTCCTGAGTAA, Mse_c GATGAGTCCTGAGTAAC, Mse_g GATGAGTCCTGAGTAAG, Mse_t GATGAGTCCTGAGTAAT, Mse_ct GATGAGTCCTGAGTAACT, Mse_cc GATGAGTCCTGAGTAACC for MseI; Eco_0 (FAM) GACTGCGTACCAATT, Eco_ac (FAM) GACTGCGTACCAATTAC for EcoRI. Aplification was cirreied out in a T100 Thermal Cycler (Bio-Rad, USA) according to the protocol: $50{ }^{\circ} \mathrm{C}$ $5 \mathrm{~s}, 60{ }^{\circ} \mathrm{C} 5 \mathrm{~s}, 70{ }^{\circ} \mathrm{C} 2 \mathrm{~min}, 95^{\circ} \mathrm{C} 1 \mathrm{~min} 30 \mathrm{~s} ; 94{ }^{\circ} \mathrm{C} 30 \mathrm{~s}, 55^{\circ} \mathrm{C} 30 \mathrm{~s}, 72{ }^{\circ} \mathrm{C} 1$ $\min 30 \mathrm{~s}$ (34 cycles); $72^{\circ} \mathrm{C} 2$ min.

Preliminarily, a $3 \mu \mathrm{l}$ DNA sample with $1 \mu \mathrm{l}$ loading dye were analyzed by $3 \%$ agarose gel electorphoresis ( $100 \mathrm{~V}$ for 3 hours, GeneRuler 100bp DNA Ladder, $0.5 \mu \mathrm{g} / \mu \mathrm{l}$, Fermentas, USA, as molecular weight marker).

Capillary electrophoresis was performed using a genetic analyzer ABI3500xl (Applied Biosystems, USA) with an integral molecular weight marker GeneScan-600 LIZ Size Standard (Applied Biosystems, USA). DNA aliquots 0.1, $0.5,1.0$ and $2.0 \mu \mathrm{l}$ were analyzed. After electrophoretic separation of fragments data were processed using BIONUMERICS 7.5 program (Applied Maths, USA).

Results. Strain L-4 was isolated after combined treatment of $A$. niger L-1 (collection of All-Russian Research Institute for Food Additives) with 1,4bis-diazoaxcetil butane (13\% solution, 3 hours) and UV-irradiation at 3.3000 erg 
per mm [23]. The strain produces citric acid at no less then $10 \mathrm{~g} \cdot \mathrm{dm}^{-3} \cdot \mathrm{day}^{-1}$ on molasses-containing medium, highly acidize sucrose-mineral medium under fermentation (no less then $16 \mathrm{~g} \cdot \mathrm{dm}^{-3} \cdot \mathrm{day}^{-1}$ ) and media containing corn, potato, wheat, rye or sorghum starch hydrolisate (no less then $18 \mathrm{~g} \cdot \mathrm{dm}^{-3} \cdot \mathrm{day}^{-1}$ ). The strain is permanently (ones a year) re-cultured on must-agar, and additionally stored as dry conidia preparation (a $10 \%$ residual moisture) for 9 months at $16-$ $20{ }^{\circ} \mathrm{C}$, and as dry conidia (a $10 \%$ residual moisture) with sporulating mycelium at -18 to $-20{ }^{\circ} \mathrm{C}$ with re-culturing each 2 years. Long-term storage at $-80{ }^{\circ} \mathrm{C}$ is provided using Station of low temperature automatic storage of biological samples (Liconic Instruments, Liechtenstein) at RCAM collection (All-Russian Research Institute for Agricultural Microbiology) [24]

Based on preliminary estimation of the obtained patterns, the Mse_ct GATGAGTCCTGAGTAACT and Eco_ac (FAM) GACTGCGTACCAATTAC; Mse_cc GATGAGTCCTGAGTAACC and Eco_ac (FAM) GACTGCGTACCAATTAC; Mse_g GATGAGTC-CTGAGTAAG and Eco_ac (FAM) GACTGCGTACCAATTAC were the most effective primers of those 12 tested as producing the highest number of DNA fragments.

The results of the automatic capillary electrophoresis (Fig.) and results of analysis formalized on amplified fragments' size for each variant (summarized in the table) are shown hereinbelow.

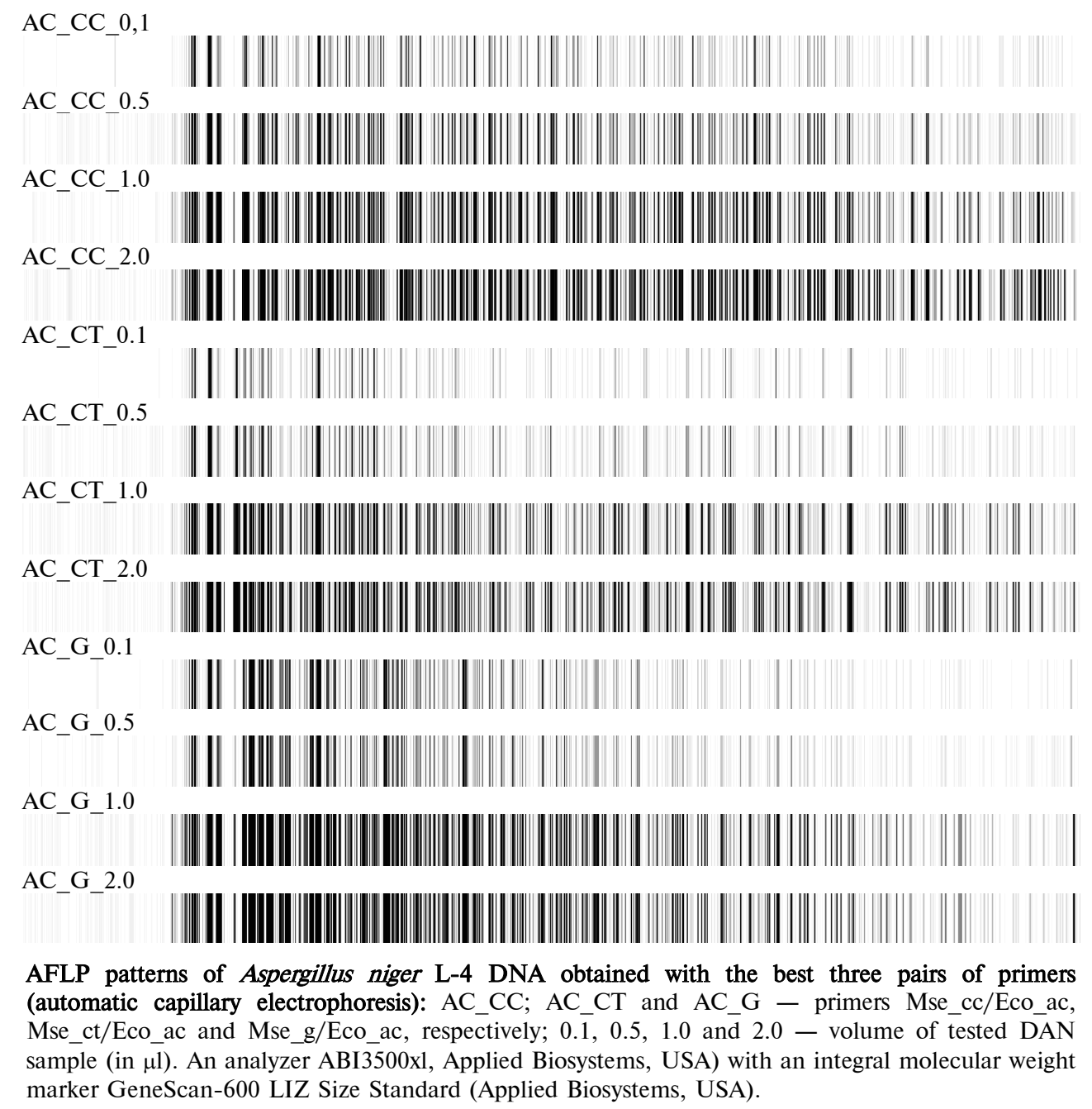


Results of Aspergillus niger L-4 AFLP-fingerptining formalized on amplified fragments' size for the best three pairs of primers

\begin{tabular}{|c|c|c|c|c|c|c|}
\hline \multirow{2}{*}{ Fragment, bp } & \multicolumn{2}{|c|}{ Mse_cc/Eco_ac } & \multicolumn{2}{|c|}{ Mse_ct/Eco_ac } & \multicolumn{2}{|c|}{ Mse_g/Eco_ac } \\
\hline & AC_CC_0.1 & $\mathrm{AC} \_\mathrm{CC} \_2.0$ & AC_CT_0.1 & $\mathrm{AC} \_\mathrm{CT} \_2.0$ & AC_G_0.1 & AC__G_2.0 \\
\hline 593.78 & 1 & 1 & 1 & 1 & 1 & 1 \\
\hline 590.69 & 1 & 1 & 1 & 1 & 1 & 1 \\
\hline 588.22 & 1 & 1 & 1 & 1 & 1 & 1 \\
\hline 580.43 & 1 & 1 & 1 & 1 & 1 & 1 \\
\hline 578.20 & 1 & 1 & 0 & 1 & 1 & 1 \\
\hline 573.78 & 1 & 1 & 1 & 1 & 1 & 1 \\
\hline 571.43 & 1 & 1 & 1 & 1 & 1 & 1 \\
\hline 569.00 & 1 & 1 & 1 & 1 & 1 & 1 \\
\hline 565.78 & 1 & 1 & 1 & 1 & 1 & 1 \\
\hline 562.58 & 1 & 1 & 0 & 0 & 1 & 1 \\
\hline 556.26 & 1 & 1 & 0 & 0 & 1 & 1 \\
\hline 549.43 & 1 & 1 & 0 & 0 & 1 & 1 \\
\hline 545.95 & 1 & 1 & 0 & 0 & 1 & 1 \\
\hline 543.39 & 1 & 1 & 0 & 0 & 1 & 1 \\
\hline 540.70 & 1 & 1 & 0 & 0 & 1 & 1 \\
\hline 534.38 & 1 & 1 & 1 & 1 & 1 & 1 \\
\hline 528.60 & 1 & 1 & 1 & 1 & 1 & 1 \\
\hline 522.89 & 1 & 1 & 1 & 1 & 1 & 1 \\
\hline 518.91 & 1 & 1 & 0 & 0 & 1 & 1 \\
\hline 517.94 & 1 & 1 & 1 & 1 & 1 & 1 \\
\hline 516.98 & 1 & 1 & 1 & 1 & 1 & 1 \\
\hline 515.58 & 1 & 1 & 1 & 1 & 1 & 1 \\
\hline 509.15 & 1 & 1 & 1 & 1 & 1 & 1 \\
\hline 497.64 & 1 & 1 & 1 & 1 & 1 & 1 \\
\hline 493.11 & 1 & 1 & 1 & 1 & 1 & 1 \\
\hline 489.14 & 1 & 1 & 1 & 1 & 1 & 1 \\
\hline 486.67 & 1 & 1 & 0 & 0 & 1 & 1 \\
\hline 483.85 & 1 & 1 & 1 & 1 & 1 & 1 \\
\hline 482.60 & 1 & 1 & 1 & 1 & 1 & 1 \\
\hline 478.11 & 1 & 1 & 1 & 1 & 1 & 1 \\
\hline 471.57 & 1 & 1 & 0 & 1 & 1 & 1 \\
\hline 468.29 & 1 & 1 & 0 & 1 & 1 & 1 \\
\hline 465.09 & 1 & 1 & 0 & 0 & 1 & 1 \\
\hline 461.17 & 1 & 1 & 0 & 0 & 1 & 1 \\
\hline 457.84 & 1 & 1 & 1 & 1 & 1 & 1 \\
\hline 453.14 & 1 & 1 & 0 & 0 & 1 & 1 \\
\hline 449.77 & 1 & 1 & 0 & 0 & 1 & 1 \\
\hline 443.78 & 1 & 1 & 1 & 1 & 1 & 1 \\
\hline 439.16 & 1 & 1 & 0 & 0 & 1 & 1 \\
\hline 435.39 & 1 & 1 & 1 & 1 & 1 & 1 \\
\hline 429.90 & 1 & 1 & 0 & 0 & 1 & 1 \\
\hline 424.21 & 1 & 1 & 1 & 1 & 1 & 1 \\
\hline 418.49 & 1 & 1 & 1 & 1 & 1 & 1 \\
\hline 417.20 & 1 & 1 & 0 & 0 & 1 & 1 \\
\hline 415.40 & 1 & 1 & 0 & 0 & 1 & 1 \\
\hline 409.27 & 1 & 1 & 0 & 0 & 1 & 1 \\
\hline 399.10 & 1 & 1 & 0 & 0 & 1 & 1 \\
\hline 392.88 & 1 & 1 & 0 & 0 & 1 & 1 \\
\hline 388.44 & 1 & 1 & 0 & 1 & 1 & 1 \\
\hline 384.48 & 1 & 1 & 1 & 1 & 1 & 1 \\
\hline 375.76 & 1 & 1 & 0 & 0 & 1 & 1 \\
\hline 356.98 & 1 & 1 & 0 & 0 & 1 & 1 \\
\hline 346.87 & 1 & 1 & 0 & 0 & 1 & 1 \\
\hline 339.88 & 1 & 1 & 0 & 0 & 1 & 1 \\
\hline 334.86 & 1 & 1 & 0 & 0 & 1 & 1 \\
\hline 326.17 & 1 & 1 & 0 & 0 & 1 & 1 \\
\hline 320.14 & 1 & 1 & 1 & 1 & 1 & 1 \\
\hline 318.12 & 1 & 1 & 0 & 0 & 1 & 1 \\
\hline 316.96 & 1 & 1 & 0 & 0 & 1 & 1 \\
\hline 316.00 & 1 & 1 & 0 & 0 & 1 & 1 \\
\hline 313.58 & 1 & 1 & 0 & 0 & 1 & 1 \\
\hline 310.47 & 1 & 1 & 0 & 0 & 1 & 1 \\
\hline 298.28 & 1 & 1 & 0 & 0 & 1 & 1 \\
\hline 285.23 & 1 & 1 & 0 & 0 & 1 & 1 \\
\hline 273.72 & 1 & 1 & 0 & 0 & 1 & 1 \\
\hline 268.38 & 1 & 1 & 1 & 1 & 1 & 1 \\
\hline 263.05 & 1 & 1 & 0 & 0 & 1 & 1 \\
\hline 256.30 & 1 & 1 & 0 & 1 & 1 & 1 \\
\hline 252.72 & 1 & 1 & 1 & 1 & 1 & 1 \\
\hline
\end{tabular}




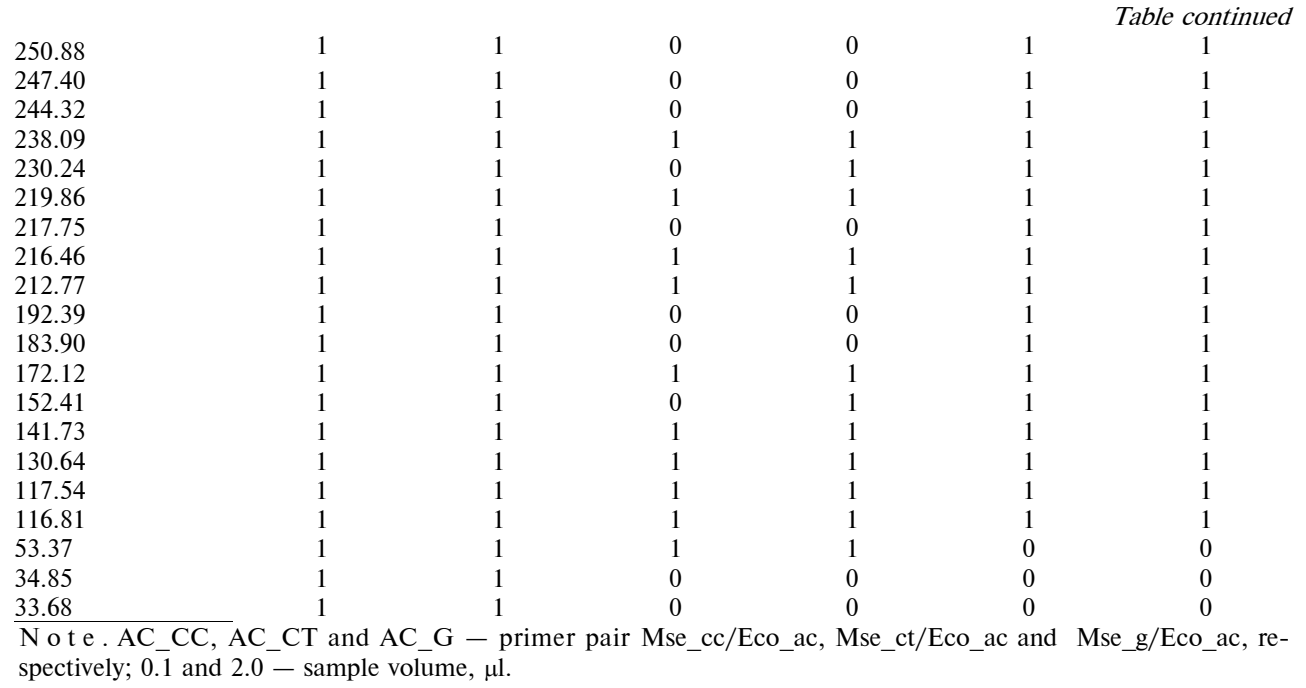

Thus, the optimal pair of primers was Mse cc GATGAGTCCTGAGTAACC and Eco_ac (FAM) GACTGCGTACCAATTAC, which produce the highest fragment number -89 fragments, from 33.68 to $593.78 \mathrm{bp}$ in size, provided the suggested technique and processing results. For each pair of primers the AFLP patterns do not depend on the volume of the sample. Note, in 2015 in large scale investigation of biodiversity of Aspergillus flavus strain the unique AFLP patterns have been found, however, the practical aspects of this phenomenon was not under consideration [25].

Thus, for the first time the AFLP-fingerptinting was optimized and used for molecular authentication of micromycete Aspergillus niger L-4 commercial strain. Obtained AFLP patterns can be used for authentication of this strain form different sources provided the place and protocol of assessment are the same as described herein. Developed method may be applied to produce «genetic passports» for other Aspergillus strains.

\section{REFERENCES}

1. S a pers G.M., M ille r R. Heated ascorbic/citric acid solution as browning inhibitor for pre-peeled potatoes. J. Food Sci., 1995, 63: $762-766$ (doi: 10.1111/j.1365-2621.1995.tb06223.x).

2. Li mbo S., P i e rglovanni L. Shelf life of minimally processed potatoes. Part 1. Effects of high oxygen partial pressures in combination with ascorbic and citric acids on enzymatic browning. Postharvest Biology and Technology, 2006, 39(3): 254.

3. Wi chrowska D., Rogozińska I., P awelzik E. Concentrations of some organic acids in potato tubers depending on weed control method, cultivar and storage conditions. Polish J. of Environ. Stud., 2009, 18(3): 487-491.

4. Ananou S., Maqueda M., Martinez-Bue no M., Gálvez A., Valdivia E. Bactericidal synergism through enterocin AS-48 and chemical preservatives against Staphylococcus aureus. Letters in Applied Microbiology, 2007, 45: 19-23.

5. Ni else n M.K., Arn e borg N. The effect of citric acid and pH on growth and metabolism of anaerobic Saccharomyces cerevisiae and Zygosaccharomyces bailii cultures. Food Microbiology, 2007, 24: 101-105 (doi: 10.1016/j.fm.2006.03.005).

6. Permitina G.V., V e revkin E.L. Sposob polucheniya kontsentrirovannogo rastvora khelata zheleza $i$ khelat zheleza. Patent 2278868 RF, MPK 51 C07F15/02, C07C229/16, C07C227/16, C05D9/02. Zayavl. 18.02.2005. Opubl. 27.06.2006 [A process for production of concentrated ferric chelate solution and ferric chelate. Application February 2, .2005. Published June 16, 2006 (in Russ.)].

7. Nikiforova T.A., Mushnikova L.N., L'vova E.B. Osnovy mikrobnogo sinteza limonnoi kisloty [Basic processes of citric acid microbial synthesis]. St. Petersburg, 2005.

8. Willems A., Doignon-Bourcier F., Coopman R., Hoste B., de Lajudie P., Gillis M. AFLP fingerprint analysis of Bradyrhizobium strains isolated from Faidherbia 
albida and Aeschynomene species. System. Appl. Microbiol., 2000, 23: 137-147 (doi: 10.1016/S0723-2020(00)80055-7).

9. W d ow i a k - W r ó b e 1 S., M a ł e k W. Genomic diversity of Astragalus cicer microsymbionts revealed by AFLP fingerprinting. J. Gen. Appl. Microbiol., 2005, 51: 369-378.

10. Safronova V., Chizhevskaya E., Bullitta S., Andronov E., Belimov A., $\mathrm{Ch}$ arles T.C., Lindströ $\mathrm{m}$ K. Presence of a novel 16S-23S rRNA gene intergenic spacer insert in Bradyrhizobium canariense strains. FEMS Microbiol. Letters, 2007, 269: 207-212.

11. A s e r s e A.A., Räs än e n L.A., A s s e fa F., Ha ile maria m A., Li nd st röm K. Phylogeny and genetic diversity of native rhizobia nodulating common bean (Phaseolus vulgaris $\mathrm{L}$.) in Ethiopia. Syst. Appl. Microbiol., 2012, 35: 120-131 (doi: 10.1016/j.syapm.2011.11.005).

12. Safronova V.I., Kimeklis A.K., Chizhevskaya E.P., B elimov A.A., An dronov E.E., Pinaev A.G., Pukhaev A.R., Popov K.P., Tikhonovich I.A Genetic diversity of rhizobia isolated from nodules of the relic species Vavilovia formosa (Stev.) Fed. Antonie van Leeuwenhoek, 2014, 105: 389-399 (doi: 10.1007/s10482-013-0089-9).

13. M a h mood T., M a sud T., I m ran M., Ah med I., Khalid N. Selection and characterization of probiotic culture of Streptococcus thermophilus from Dahi. Int. J. Food Sci. Nutr., 2013, 64(4): 494-501 (doi: 10.3109/09637486.2012.749840).

14. Li Y., Canchaya C., Fang F., Raftis E., Ryan K.A., van Pijkeren J.-P., van Sinderen D., O' T o ole P.W. Distribution of megaplasmids in Lactobacillus salivarius and other lactobacilli. J. Bacteriol., 2007, 189(1): 6128-6139 (doi: 10.1128/JB.00447-07).

15. K u d o Y., O k i K., W a t a $\mathrm{n}$ a b e K. Lactobacillus delbrueckii subsp. sunkii subsp. nov., isolated from sunki, a traditional Japanese pickle. Int. J. Syst. Evol. Microbiol., 2012, 62: 26432649 (doi: 10.1099/ijs.0.037051-0).

16. Martínez-Peca M.D., Castro-Escarpulli G., Aguilera-Arreola M.G Lactobacillus species isolated from vaginal secretions of healthy and bacterial vaginosisintermediate Mexican women: a prospective study. BMC Infect. Dis., 2013, 13: 189-197 (doi: 10.1186/1471-2334-13-189).

17. Kathuria S., Sharma C., Singh P.K., Agarwal P., Agarwal K., Hagen F., $\mathrm{M}$ e is J.F., Chow dhary A. Molecular epidemiology and in-vitro antifungal susceptibility of Aspergillus terreus species complex isolates in Delhi, India: Evidence of genetic diversity by amplified fragment length polymorphism and microsatellite typing. PLoS One, 2015, 10(3): e0118997 (doi: 10.1371/journal.pone.0118997).

18. Chiotta M.L., Reynoso M.M., Torres A.M., Combina M., Chulze S.N. Molecular characterization and toxigenic profile of Aspergillus section Nigri populations isolated from the main grape-growing regions in Argentina. J. Appl. Microbiol., 2011, 110(2): 445-454 (doi: 10.1111/j.1365-2672.2010.04898.x).

19. Xia X., Lie T.K., Q ian X., Zheng Z., Huang Y., Shen Y. Species diversity, distribution, and genetic structure of endophytic and epiphytic Trichoderma associated with banana roots. Microb. Ecol., 2011, 61(3): 619-625 (doi: 10.1007/s00248-010-9770-y).

20. Larralde-Corona C.P., S a ntiago-M ena M.R., S i fuentes-Rincón A.M., Rodríguez-Luna I.C., Rodríguez-Pérez M.A., Shirai K., Narváez$\mathrm{Z}$ a p a t a J.A. Biocontrol potential and polyphasic characterization of novel native Trichoderma strains against Macrophomina phaseolina isolated from sorghum and common bean. Appl. Microbiol. Biotechnol., 2008, 80(1): 167-177 (doi: 10.1007/s00253-008-1532-0).

21. Pa u O., S c hö n s we t t e r P. Amplified fragment length polymorphism: an invaluable fingerprinting technique for genomic, transcriptomic, and epigenetic studies. Methods Mol. Biol., 2012, 862: 75-87 (doi: 10.1007/978-1-61779-609-8_7).

22. Safronova V.I., Chizhevskaya E.P., Andronov E.E. Razrabotka metodiki molekulyarno-geneticheskoi pasportizatsii shtammov sel'skokhozyaistvennykh mikroorganizmov s pomoshch'yu AFLP-fingerprintinga [AFLP-fin-gerprinting method for a molecular-genetic certification of agricultural microorganisms]. Sel'skokhozyaistvennaya Biologiya [Agricultural Biology], 2012, 6: 116-121 (in Russ.).

23. Ermakova V.P., Shcherbakova E.Ya., Vasilinets I.M., Fin'ko V.M., Shushk e vich T.N. Patent 975799 RF, MKI S12N 15/00, S 12R 7/48 Shtamm griba Aspergillus niger L-4 - produtsent limonnoi kisloty. Zayavl. 13.06.80. Opubl. 23.11.82 [Aspergillus niger L-4 strain, a producer of citric acid. Application June 13, 1980. Published November 23, 1982 (in Russ.)].

24. Safronova V., Tikhonovich I. Automated cryobank of microorganisms: Unique possibilities for long-term authorized depositing of commercial microbial strains. In: Microbes in applied research: current advances and challenges. A. Mendez-Vilas (ed.). World Scientific Publishing Co., Singapore, 2012: 331-334 (doi: 10.1142/9789814405041_0066).

25. S ingh D., Radhakrishnan T., Kumar V., Bagwan N.B., Bas u M.S., Do b a ri a J.R., M is h r G.P., Chand a S.V. Molecular characterisation of Aspergillus flavus isolates from peanut fields in India using AFLP. Braz. J. Microbiol., 2015, 46(3): 673-682 (doi: $10.1590 / \mathrm{S} 1517-838246320131115)$. 